\title{
COVID-19, Norms, and Discrimination against Female Gender in Nigeria: Focus on Implications for Mental Health Counselling
}

\author{
Chinedu Hilary Joseph ${ }^{1, *}$, Henrietta ljeoma Alika ${ }^{2}$, Anikelechi ljeoma Genevieve ${ }^{3}$ and \\ T.D. Thobejane ${ }^{4}$
}

${ }^{1}$ Department of Guidance and Counselling, Faculty of Education, Federal University Oye-Ekiti, Ekiti State, Nigeria

${ }^{2}$ Department of Educational Evaluation and Counselling Psychology, Faculty of Education, University of Benin, Nigeria

${ }^{3}$ Department of Integrated Science, Nnamdi Azikiwe University, Awka, Nigeria

${ }^{4}$ University of Venda, South Africa

\begin{abstract}
The COVID-19 outbreak is inflicting different societies of the world with an untold and unprecedented hardship. However, the extent of impacts is bound to differ across groups, gender, economies, and countries. Given how the pandemic affects particular groups, this paper focuses on girls/young women and how Covid-19 may further strengthen gender norms and discriminations as risk factors of their mental health. In some societies, right from birth, the life experiences of the female child differ from the male child. At every stage of development, girls are more likely than boys to confront a host of challenges associated with discrimination and norms, which are gender-based. With the effects of the current pandemic evident in reduced access to health care, education, teenage pregnancy, and being vulnerable, young women and girls are more at the receiving end of their impacts. These stand as hindrances to the girl child's mental health because they tend to constitute anxiety, depression, self-harm, or even suicide and weakens her will power to make proper adjustment to life issues. This paper concludes that given that the impacts of COVID-19 are not gender-blind (affecting both genders), therefore the designing policy responses to the current pandemic should not be either. As we all continue to face this overwhelming Covid-19 pandemic, the study recommends that the vulnerable (especially girls and young women) should not be neglected or ignored. This is possible by not forgetting the inequalities that may worsen the conditions of girls because of the crisis.
\end{abstract}

Keywords: Covid-19, Gender, Discrimination, Mental Health, counselling, and Nigeria.

\section{INTRODUCTION}

Children are exposed to some experiences and circumstances such as abuse and neglect, which may cause them to be particularly vulnerable to mental health challenges and led to the increasing demand for children's mental health care and services. The rise in children's mental health difficulties may be ascribed to the growing pressures of attaining adolescence, worry over passing an examination and getting a job, poverty, and insecurity, as well as concerns about their body image and the indiscriminate use of social media. The girl child is not exempted in this issue as she is embraced by various traditional and cultural experiences that constitute maltreatments precipitated by gender expectations and roles leading to discriminations.

There appears to be a great deal of interest in norms, especially the type based on gender, because of their role in underpinning practices that are seen as challenging in some way; for example, they contribute

*Address correspondence to this author at the Department of Guidance and Counselling, Faculty of Education, Federal University Oye-Ekiti, Ekiti State, Nigeria; Tel: +2348066205266; E-mail: nedunwa28@gmail.com to poor health outcomes or uphold discrimination and norms. The lingering and accepted norms which degenerated into discriminatory frameworks that provide a veneer of legitimacy to some practices, such as child marriage, shape a girl's life span. These norms appear to be the fundamental drivers of discrimination. They must be checkmated and challenged everywhere due to their role in denying women their rights, such as rights to education, family property, and consent to marry and have sex. However, those granted liberty, such as being educated and marrying at a mature age, have greater advantages and are able to contribute meaningfully to their community. Girls and women who are educated and marry later are more likely to earn an income. Women who have their babies later in life are healthier, raise healthier educated children, and help end the perpetual cycles of inequality, discrimination, abuse, and poverty. Consequently, the above positions, coupled with the documented records of depression and anxiety disorders among young girls and women, have necessitated the need to address the impacts of norms and discriminations based on gender that may negatively affect the mental health of the girl child. 


\section{THE CONCEPT OF GENDER}

Gender denotes a range of socially created roles and interactions, personality attributes, attitudes, values, behaviours, relative power, and influence that society ascribes to males and females. Gender is a learned uniqueness and a social construct which, over time, varies and usually changes within and across cultures that refers not just to male and female roles but also the relationship between them. It is a social concept that influences roles, attitudes, responsibilities, and behavioural dispositions of girls, boys, women, and men in most developed and developing societies.

It is believed that gender has created room for the emergence of discrimination and has been regarded as the most endemic form of discrimination. Gender is a critical determinant of mental health and mental illness, but gender-specific determinants and mechanisms have received less attention than other correlates such as morbidity, which has enjoyed more research as predictors of mental health status. Justifying the role of gender issues in mental health, [1] explains that gender determines the differential power and control men and women have over the socioeconomic determinants of their mental health and lives, their social position, status and treatment in society and their susceptibility and exposure to specific mental health risks.

\section{GENDER NORMS}

Gender is often acknowledged as one of the major social determinants of health status. Sometimes, gender is viewed as something that an individual is. However, it is currently described as something that a person does through their behaviours towards and interactions with others. The term 'norm' is used simply to mean a common practice, what most people do in a particular context. It is often used to describe practices, such as early marriage or female genital mutilation. This paper thus refers to norms as the informal rules governing behaviour. Norms are vital determinants of social stratification as they reflect and reproduce relations that empower some groups of people with material resources, authority, and entitlements while marginalising and subordinating others by normalising shame, inequality, indifference, or invisibility [2].

Gender norms are social norms that are specifically associated with gender differences. In this paper, the term 'gender norms' refers to informal rules and shared social expectations that distinguish expected behaviour based on gender. For example, a common gender norm is that women and girls will and should do the majority of home chores. Gender norms are powerful, pervasive values and attitudes about gender-based social roles and behaviours that are deeply embedded in social structures and manifest at various levels: within households and families, and in communities, neighbourhoods, and societies. They ensure the maintenance of social values and practices, punishing or sanctioning nonconformity to those norms. They also interact at various levels to produce outcomes that are frequently inequitable [3]. These norms influence behaviours and reflect complex social structures within societies. They can play a powerful role in a person's life since deviating from the norms associated with one's biological sex can be met with criticism from peers, social exclusion, and sometimes even emotional or physical violence [4].

Gender norms reflect in the form of submissive femininity, dominant masculinity, men's use of violence against women and girls, internalised acceptance of male superiority/ female inferiority, acceptance of men's control, and deprioritisation of violence against women and girls. They are kind of a box. Everyone seems to be living in these boxes, and getting out or doing the opposite is like committing a crime. The norms make women and men remain in this box. Conforming to gender norms can have implications for a person's health because certain behaviours considered to be normative for a particular gender may be associated with health outcomes. It appears a norm for men in some societies is to drink alcohol excessively, to be strong, tough, have lots of girls, have money, be a player or a pimp, in control, dominate other men, and if they are not, any of those, then they may be labelled soft or weak. Consequently, no male person wants to be any of those. Similarly, for women to remain in the box, they have to be modest, maternal, obedient, and naïve. These norms categorise them as less likely to carry condoms, less likely to talk about sex (especially with boys), less likely to have skills/confidence/knowledge to negotiate, more likely to defer to male sexual prerogatives, more likely to tolerate male infidelity and more likely to submit to partner violence. The lingering effects of these informal rules (norms) seem to rob women of the power to control many parts of their lives and contribute meaningfully to their community.

\section{GENDER DISCRIMINATION}

Discrimination is simply the unequal treatment of people on the basis of the characteristics that 
differentiate them. Some norms, stereotypes, prejudices, and/or different forms of racism precipitate discrimination. Gender discrimination, as the name implies, is the unfair treatment of women and denial of opportunities, and violation of their rights. In the Convention on the Elimination of all Forms of Discrimination Against Women (CEDAW), discrimination against women was defined as "any distinction, exclusion or restriction made on the basis of sex which has the effect or purpose of impairing or nullifying the recognition, enjoyment or exercise by women, irrespective of their marital status, on the basis of equality of men and women, of human rights and fundamental freedoms in the political, economic, social, cultural, civil or any other field" [5].

Despite the numerous gender discrimination laws and court rulings, women are subjected to unequal treatment in all spheres of life all over the world [6]. One form of discrimination against women or the other is still found in most of the countries that claim to be advocates of women's rights. Compensation for women's efforts and contributions at the workplace and in society are often ignored and overlooked. In some developing and developed societies of the world, women's rights to education, health care, participation are trampled upon and denied. While in some settings, even when they may be capable than men, they are still denied rights over property and are not opportune to maximise their potentials and talents. Some women are considered inferior to men both physically and mentally, and their lives are totally controlled by men. Some are confined to their houses and can only go out when escorted by a male member of the family and generally considered weak not only physically but also mentally.

Discrimination against girls begins at birth or, in some cultures, even before they are born, as a result of female feticide, infanticide, and neglect [7]. Son preference is a consequence of deeply embedded discrimination against girls and the higher value and status granted to boys because they carry on the family name, bring resources into the family (wife and dowry), and perform funeral rites [8]. In Nigeria, the birth of a son is considered a blessing and is celebrated while a daughter is a burden in some tribes, and the practice of son preference has also been linked with adverse health outcomes for girls through the privileged access to nutrition preferring boys [9].

Female Genital Mutilation (FGM) is another form of discrimination suffered by girls and women. Although it might be normal in some societies, but it is a vital human right and public health issue. Approximately 100 to 140 million girls and women in the world have experienced FGM, with more than three million girls in Africa annually at risk of the practice [10]. It poses a severe risk to the physical and psychological health of girls, constitutes a major violation of their human rights, and is a major threat to the attainment of the MDGs $[11,12]$. Studies such as [13] suggest that FGM is likely to cause a range of emotional disturbances, forging the way to psychiatric disorders, especially post-traumatic stress disorder (PTSD).

In many parts of the world, young girls (sometimes as young as age six) are forced into early marriage (often with men many years older) by their families and communities, often justified by religious beliefs or tradition [14, 15]. Early and forced marriage comes with its own implications. Some young female children are trapped in relationships that deny them of their fundamental human rights, terminate their educational advancement opportunities, limit their freedom, increase their being prone to different levels of violence and health challenges, and restrain their economic advancement/opportunities. Consequently, they are left to be at the mercy of some adverse physical, mental, and emotional consequences. In some cases, girls are forced to migrate to escape the early marriage. This is very risky because they may be trafficked in their effort to get a safe place. Early marriage can be accompanied by early pregnancy, which may pose severe threats to the mental health and psychosocial development of the girl child.

In some cultures, girls are murdered by male members of their families if it is suspected that the family code has been negatively affected, and the female is perceived to have brought dishonour against the family [16, 17]. Sometimes, these murders are committed on girls who are viewed by the community as contravening the prevailing social and cultural norms such as premarital sex, being a victim of sexual assault or rape, not agreeing to enter an arranged marriage, suspicions of adultery, requesting a divorce, seeking to escape marital violence, or for going beyond their society's cultural norm and exercising their right to select their own life partner, career, or even clothing $[18,19]$.

\section{THE INTENSIFYING ROLE OF COVID-19 IN MENTAL HEALTH OF GIRLS}

In the last lap of 2019, a respiratory infection from an unknown virus appeared in Wuhan, China. The 
early laboratory experiment and findings revealed that it was an infectious disease named Coronavirus disease 2019 (abbreviated as COVID-19), which is caused by severe acute respiratory syndrome coronavirus 2 (SARS-CoV-2). As of June 2020, Covid19 has spread to over 213 countries and territories around the world. While there are ongoing attempts to checkmate its spread, which is basically transmitted through humans, it has constituted health hazards, economic uncertainties, unexpected closures of economic sources, and disruptions with over 7 million confirmed cases and more than 400,000 deaths (worldometers.info).

The outbreak of the coronavirus pandemic is a prime concern in Nigeria, and its spread necessitated a lot of drastic decisions and choices among different national governments in which Nigeria was not exempted. It will be remembered that in the early weeks of the emergence of Covid-19 in Nigeria, a range of government-sanctioned and structure-shifting risk-control orders such as international airport closures, nationwide closure of all schools, and an initial two-week lockdown of three major states - Lagos, Abuja, and Ogun were issued by the government to curtail the spread of the novel coronavirus diseaseCOVID-19. The lockdown was later renewed every two-weeks, still continuing and extended to all states of the federation.

The pandemic brought about the inevitable lockdown, which led to a period of suspension of academic activities in schools nationwide. It is a known fact the school is home to a legion of minors, especially girls. According to UNESCO, almost 40 million learners have been affected by the nationwide school closures in Nigeria, of which over 91 per cent are primary and secondary school learners [20]. Most especially, consequent upon school closures triggered by the pandemic lockdown, many girls are inevitably homebound, and the probability of household responsibilities falling on them exacerbates their burden. There is a likelihood that they will suffer some certain disadvantages due to their gender, which is compounded by poverty and other discriminatory factors, such as violence, abuse, child marriage, limited opportunities for education and early pregnancy, and stereotyped roles in caregiving.

Covid-19 has deepened pre-existing inequalities and exposed gaps in our systems, and its effects have been exacerbated for women and girls [21]. Girls will be particularly affected by the secondary impacts of the outbreak due to harmful social norms and double discrimination based on age and gender. In this pandemic, the lives of girls face extreme stress from health encumbrances, crowding, and isolation. Obviously, the attempts made to curtail the disease have worsened existing inequalities, forcing girls out of school and exposing them to increased risk of violence and abuse in their homes. Covid-19 did not limit its devastating effects and impacts as it extended to threatening the mental health of girls and young women. Women trapped in an escalating cycle of tension, power, and control are vulnerable to experiencing varied mental health concerns, including depression, anxiety, and trauma [21]. And now, as the world is trying to combat Covid-19, the mental health of girls is being tested more than ever [22] because health care providers may not be readily available to help girls with issues like anxiety or depression, even though this pandemic is most likely to amplify those conditions.

\section{GENDER NORMS, DISCRIMINATION AND MENTAL HEALTH OF THE GIRL CHILD}

Describing mental health is challenging as it is conceptually ambiguous. However, the holistic definition from the World Health Organization [23] was adopted in this paper, and it describes mental health as "a state of well-being in which every individual realises their own potential, can cope with the normal stresses of life, can work productively and fruitfully, and is able to make a contribution to their community. Mental health is how people think, feel, and act, which affects how they handle stress, relate to each other and make decisions. It influences how an individual perceives him/herself, their lives, and others. As child health research continues to increase, there is a growing recognition of mental health's importance to the girl child's overall health and well-being, both now and later in life.

Good mental health is critical to ensuring healthy transitions to adulthood, with implications for overall well-being, growth and development, self-esteem, positive education outcomes, social cohesion, and resilience in the face of future health and life changes [24], and it enables children to think clearly, develop socially and learn effectively. Academics, practitioners, and advocates of stable mental health increasingly recognise its importance to the overall well-being of the girl child and complex linkages with gender issues as well as discrimination. Some trends, such as discrimination and norms based on gender, pose a great threat to the self-esteem and development of 
young people, especially girls. Not appropriately addressing these gender stereotypes can harm the girl child by increasing their vulnerability. Therefore, understanding the girl child's unique and common vulnerabilities to mental health risks, including the impacts of harmful gender norms and the factors that can protect and enhance their mental health and wellbeing, are indispensable and crucial when considering appropriate regulations interventions.

Gender norms as informal rules and shared social expectations that distinguish expected behaviour based on gender. In some societies, they have roles to play in whether an individual's needs are acknowledged and whether people can realise their rights. The role of gender norms on health behaviours is typically slightly different for men and women. Risky health behaviours are expressions of masculinity for men, but, for women, gender norms can constrain women's power and limit their ability to take control of their health [25]. Its other effects may include reduced power to make a decision over family deliberations or limited physical activity out of a concern for appearing less feminine.

Gender norms are not necessarily harmful to girls' well-being and development - for example, they can enable girls to develop specific skills and knowledge that will be useful to them during adolescence and adult life. But because some gender norms reflect and contribute to inequalities in the distribution of power and resources that often disadvantage women and girls, many gender norms do, in practice, limit girls' development opportunities and undermine their wellbeing [26]; therefore, they could be harmful. In other words, norms limiting girls' potentials could be harmful to their well-being because they do not support girls to contribute meaningfully to their society, which the definition of mental health depicts. Harmful gender norms may result in risky behaviours, violence, substance abuse, the pursuit of multiple sexual partners, and the domination of women. They affect not only men and women but also their families and communities. Harmful gender norms, including those that influence sexual and power relations, lead to behaviours that put men, women, boys, and girls at risk.

Risk factors that are gender-specific and typical of women include gender-based roles, sexual abuse, low social status, socioeconomic disadvantage, stressors, income equality, continuous responsibility for the care of others, trafficking, glass ceiling in different professions, female genital mutilation, forced prostitution appear to be predictors of depression, anxiety and stress disorder which accounts for women's poor mental health. These factors are reinforced by gender norms and discrimination. Gender norms can reinforce girls' and young women's unequal position in relationships, reducing their ability to refuse sexual advances and negotiate safer sexual practices, including condom use. Nearly $30 \%$ of adolescent girls age 15-19 report lifetime physical and/ or sexual violence by an intimate partner [27]. These norms and discriminations constitute a variety of social and cultural factors that place women and girls at risk of poor health. They equally lead to severe life events that create a sense of humiliation, loss, entrapment, and inferiority, which can predict depression, a common indicator of mental health problems.

Adolescent girls and young women often lack a full range of opportunities and are devalued because of gender bias and low social status. Due to genderspecific factors, girls are more likely than boys to be married as children, drop out of school, and experience forced sexual initiation [24]. These factors negatively affect adolescent girls and boys, but particularly limit girls' ambitions and opportunities. For example, girls who marry too early may face diminished opportunities for education and paid employment, reduced ability to control matters pertaining to them and decision-making capacity, as well as increased risk of different kinds of violence. Stigma and discrimination increase vulnerability to depression and suicide, and stigma and discrimination can be fueled by gender norms [28]. Discrimination experienced by the girl child who was displaced by the crisis, raped, and trafficked can cause them to experience depression, anxiety, self-harm, loss of freedom, rejection, humiliation, and stigmatisation that may lead to suicide.

The gender-based norms, discrimination, and inequities earlier highlighted subject girls to health and mental health problems, including unwanted pregnancy, unsafe abortions, maternal mortality, sexually transmitted infections, depression, disorders associated with body image, and other manifestations of psychological distress [12, 24, 29]. These reports are reflections of maladjustments and poor mental health. No one with the right frame of mind would want to harm $\mathrm{him} /$ herself or commit suicide. These, therefore, call for urgent measures toward curtailing the excesses of gender norms and discriminations as they contribute to depression, anxiety, and disorders, which are detrimental to the mental health of the girl child. 


\section{IMPLICATION FOR MENTAL HEALTH COUN- SELLING}

Gender norms and discriminations have psychological implications as they expose their victims to symptoms such as depression, anxiety, and disorders. Consequently, there is a need for psychological assistance to help the girl child cope maximally with the effects of discrimination and violence. The existing literature gaps reveal that there is no sufficient advocacy against gender-based norms and discrimination in relation to the mental health of the girl child. Mental health counselling gives room for cushioning the psychological effects of gender-based norms. Mental health counselling helps people cope with mental health conditions and issues such as depression, anxiety, disorders, low self-esteem, or anger. Hence, this study implies that

The mental health counsellor should help the girl child be mindful of the socialisation processes and recognise existing norms and discriminations and their impacts to affirm valued attributes in themselves to make them less vulnerable. He/she is expected to be abreast of new developments in contemporary social forces and their interaction with gender, social, and cultural identities.

The mental health counsellors should help the girl child understand the impacts of bias, norm, and discrimination so she can better identify and differentiate those that are external or internal and overcome them to attain a healthy functioning. They are urged to gain specialised education, training, and experience with issues particularly relevant to the experiences and problems of the girl child in terms of discrimination, violence, and norms.

They should look out for and adopt interventions and approaches found to be effective in treating issues that are unique to the experiences and concerns of the girl child. He/she should strive to acquaint him/herself with and utilise relevant mental health education and resources such as safe houses, women's centres, shelters, and self-help groups for the girl child.

The mental health counsellor is admonished to engage in an ongoing examination of values, attitudes, and stereotypes towards the girl child to ensure that his/her dispositions support optimal practice. He/she should help eliminate barriers to psychological treatments for the girl child and help them gain access to quality mental health services.

\section{CONCLUSION}

There is evidence in the literature that gender norms and discrimination against women and girls contribute to poor mental health in the form of anxiety, depression, self-harm, and suicide. Hence, failure to prioritise the mental health care of the girl child will negatively influence not only the health of the current generation but also that of future generations of women. Therefore, it is imperative to checkmate the impacts of gender norms and discrimination to improve the girl child's mental health.

More so, gender discrimination has been with us and lingered much longer. Its persistent effect is only intensified in times of crisis, such as the outbreak of COVID-19. In understanding the impacts of and designing policy responses to the current pandemic, it will be of utmost urgency and importance to pay undivided attention to the prevailing gender discriminations and how they are likely to deepen the effects of the pandemic further. Besides, considering the involvement of women in caregiving and the reality of serving as wives and mothers coupled with the general assumption that women stereotypically manages the home, they should be actively helped so as to support them in coping with the pandemic.

It is hoped that the awareness raised about the distinct mental health challenges that face young girls and how these challenges are perhaps precipitated by gender-based norm and discrimination as well as the lingering Covid-19, can help to intensify interest in the well-being of the girls and young women and create the need to chart a new course of action for initiating suggestions on risks and protective factors of genderbased norms and discrimination as well as spur future research and action. As we all face this devastating Covid-19 pandemic, the vulnerable (especially girls and young women) should not be neglected or ignored. This is possible by not forgetting the inequalities that may worsen the conditions of girls because of the crisis.

\section{RECOMMENDATIONS}

The findings from literature left much to be desired with respect to the mental health of young women and girls; hence comprehensive and immediate actions to curtail the lingering effect of Covid-19 and the harmful gender-based norms, discriminations, and practices against females need to be initiated to ensure gender equality by: 
Advocating a renewed attention to meeting the health care needs of the girl child through strengthening health systems as well as prioritising these needs in the global health care agenda and integrating it into general health care policies.

Monitoring every gendered driver of mental health problems related to girls and strengthening support and awareness-raising at the community, local, national, and international platforms to challenge gender-based norms, practices, and combat discriminatory attitudes and dispositions.

Stimulating and fostering girls' mindfulness and involvement in their own lives and in their communities while acknowledging that sustaining the advancement of women is not feasible without proper attention to the rights of the girl child. Meeting the needs of girls and shielding them through responsive, equitable, gendertransformative, and protective advocacy of their human rights.

Ensuring that public health infrastructures and services are fortified and women's mental health is a priority since they are home-bound due to the lockdown and also facing a more unprecedented and sharp increase in workload and caregiving roles/tasks despite less freedom and social and economic security.

Analysing existing evidence and undertaking recent research to understand how gender norms and discriminations play out in our homes, streets, and schools might influence the mental health of girl children.

\section{REFERENCES}

[1] World Health Organization, WHO, Gender and women's mental health 2019. Retrieved from www.who.int/mentalhealth/prevention/genderwomen/en/ on March 5th, 2019.

[2] Overseas Development Institute, ODI, Social norms, gender norms and adolescent girls: a brief guide. Knowledge to action: Understanding gender norms that affect adolescent girls, 2015. Accessed from www.odi.org on $18^{\text {th }}$ March, 2019.

[3] Keleher H, Franklin L. Changing Gendered Norms about Women and Girls at the Level of Household and Community: A Review of the Evidence. Global Public Health 2008; 3(1): 42-57.

https://doi.org/10.1080/17441690801892307

[4] Courtenay WH. Constructions of masculinity and their influence on men's well-being: a theory of gender and health. Social Science and Medicine 2000; 50(10): 1385-401. https://doi.org/10.1016/S0277-9536(99)00390-1

[5] Convention on the Elimination of all Forms of Discrimination Against Women (CEDAW) CEDAW-Factsheet 2015. Accessed from https://unwomen.org.au>2015/11>CE

[6] Zarar R, Bukhsh MM, and Khaskheli WA. Causes and Consequences of Gender Discrimination against Women in Quetta City. Arts Social Science Journal 2017; 8(3): 1-6. https://doi.org/10.4172/2151-6200.1000277
[7] Rafferty Y. International Dimensions of Discrimination and Violence against Girls: A Human Rights Perspective. Journal of International Women's Studies 2013; 14(1): 1-23. Available at: http://vc.bridgew.edu/jiws/vol14/iss1/1

[8] Lamichhane $P$, Harken T, Puri M, Darney PD, Blum M, Harper CC, Henderson JT. Sex-selective abortion in Nepal: A qualitative study of health workers' perspectives. Women's Health Issues 2011; 21(3): S37-S41. https://doi.org/10.1016/j.whi.2011.02.001

[9] United Nations (UN). Fact sheet No. 23, harmful traditional practices affecting the health of women and children. Office of the High Commissioner for Human Rights (UNHCR) 1995. Retrieved from www.unhcr.org/refworld/docid/479477410. $\mathrm{html}$

[10] World Health Organization (WHO). Female genital mutilation: Fact sheet No. 241, 2010. Retrieved from www.who.int/ mediacentre/factsheets/fs241/en/

[11] United Nations Population Fund (UNFPA) Women's and children's rights: Making the connection. New York, NY: Author, 2011. Retrieved from www.unfpa.org/webdav/ site/global/shared/documents/publications/2011/WomenChild ren_final.pdf

[12] United Nations International Children's Emergency Fund, UNICEF The state of the world's children 2011: Adolescence - An age of opportunity. New York, NY: 2011. Retrieved from www.unicef.org/sowc2011/fullreport.php

[13] Behrendt A, Moritz S. Posttraumatic stress disorder and memory problems after female genital mutilation. The American Journal of Psychiatry 2005; 162(5): 1000-1002. https://doi.org/10.1176/appi.ajp.162.5.1000

[14] Levine R, Lloyd CB, Greene M, Grown C. Girls count: A global investment and action agenda. Washington, D.C.: The Center for Global Development, 2009. Retrieved from www.coalitionforadolescentgirls.org/sites/default/files/Girls_C ount_2009.pdf

[15] United Nations Population Fund. (UNFPA). Marrying too young: End child marriage. New York, 2012. Retrieved from http://www.unfpa.org/public/home/publications/pid/12166

[16] Kogacioglu D. The tradition effect: Framing honour crimes in Turkey. Journal of Feminist Cultural Studies 2004; 15(2): 119-151.

https://doi.org/10.1215/10407391-15-2-118

[17] Santos-Pais M. Protecting children from harmful practices in plural legal systems. New York 2012, Office of the Special Representative of the Secretary-General on Violence Against Children. Retrieved from http://srsg.violenceagainstchildren. org/sites/default/files/publications final/SRSG Plan $h$ armful_practices_report_final.pdf

[18] Sadik N. Ending violence against women and girls, United Nations Population Fund Report, 25-30 2007. Retrieved from http://womennewsnetwork.net/2011/06/15/site-dignityhonorviolence/

[19] United Nations Assistance Mission in Afghanistan-Human Rights (UNAMA-HR). Harmful traditional practices and implementation of the law on Elimination of violence against women in Afghanistan. Kabul, Afghanistan: 2010. Retrieved from http://unama.unmissions.org/Portals/UNAMA/ Publication/HTP\%20REPORT_ENG.pdf

[20] Obiakor T, Adeniran AP. Covid-19: Impending Situation Threatens to Deepen Nigeria's Education Crisis. Centre for the Study of the Economy of Africa (CSEA) 2020.

[21] Matthews R. Covid-19: Why are women more vulnerable to mental health issues? 2020 retrieved from https://feminisminindia.com/2020/05/05-Covid-19-womenvulnerable-mental-health-issues/ on 11th June, 2020.

[22] Whelan K. Disaster and Conflict: Girls' mental health and Covid-19 2020. Retrieved from https://www.planusa.org/ girls/girls-mental-health-and-Covid-19 on 12th June, 2020. 
[23] World Health Organization, WHO. Mental health action plan 2013-2020. Geneva, Switzerland: World Health Organization; 2014.

[24] United Nations International Children's Emergency Fund, UNICEF. Progress for Children: A report card on adolescents. New York, NY: 2012. Retrieved from www.unicef.org/publications/files/Progress for_Children No ._10_EN_04272012.pdf on 13th March, $20 \overline{19}$.

[25] Phillips SP. Defining and measuring gender: A social determinant of health whose time has come. International Journal for Equity in Health 2005; 4(1): 11. https://doi.org/10.1186/1475-9276-4-11

[26] Overseas Development Institute, ODI. Social norms, gender norms, and adolescent girls: a brief guide. Knowledge to action: Understanding gender norms that affect adolescent girl 2005. Accessed from www.odi.org on $18^{\text {th }}$ March, 2019.
[27] World Health Organization, WHO. Global and regional estimates of violence against women. Prevalence and health effects of intimate partner violence and non-partner sexual violence. Geneva 2013.

[28] Kapungu C, Petroni S. Understanding and tackling the gendered drivers of poor adolescent mental health. Washington, DC: International Center for Research on Women 2017.

[29] Grover A. Interim report of the Special Rapporteur of the Human Rights Council on the right of everyone to the enjoyment of the highest attainable standard of physical and mental health to the United Nations General Assembly (A/66/254) 2011. Retrieved from www.acpd.ca/wpcontent/uploads/2012/08/SR-Right-to-Health-Criminalizationof SRHR-2011.pdf

Received on 23-10-2020

Published on 26-02-2020

https://doi.org/10.6000/2292-2598.2021.09.01.3

(C) 2021 Joseph et al.; Licensee Lifescience Global.

This is an open access article licensed under the terms of the Creative Commons Attribution Non-Commercial License (http://creativecommons.org/licenses/by-nc/3.0/) which permits unrestricted, non-commercial use, distribution and reproduction in any medium, provided the work is properly cited. 